\title{
Effect of supplementation of garlic and cinnamon in hypertensive subjects
}

ABSTRACT : The study was undertaken to assess the effect of garlic and cinnamon in hypertensive subjects. Garlic powder contains allicin and cinnamon contains cinnamonaldehydes. They have the hypertension reducing property. A sample of 60 hypertensive subjects was selected purposively. Their information regarding socio-economic status and health status was collected through questionnaire. They were divided into two groups, experimental and control, 30 in each group. The blood pressure reading was taken initially for all the 60 subjects. The prepared garlic powder and cinnamon powder was given to experimental group continuously for 60 days and told them to use in a day in any recipe or cinnamon powder can be taken in a coffee or tea. Reading of systolic and diastolic blood pressure at $0,15,30,45$ and 60 days were recorded for both the groups. The collected data was analysed statistically and it was concluded that the consumption of $0.5 \mathrm{~g}$ of dry garlic powder and $0.5 \mathrm{~g}$ of cinnamon powder continuously for 60 days has positive effect in hypertensive subjects. Consumption of garlic and cinnamon powder had significantly positive results than only consumption of garlic powder.

KEY WORDS: Hypertension, Systolic and diastolic blood pressure, Cinnamon, Garlic, Hypertensive subjects

- HOW TO CITE THIS PAPER : Farzana, Farooqui Hafeez (2015). Effect of supplementation of garlic and cinnamon in hypertensive subjects. Asian J. Home Sci., 10 (2) : 395-399. 